\title{
Análise morfológica e morfométrica das gônadas de preguiça (Bradypus variegatus Schinz, 1825) ${ }^{1}$
}

\author{
Mariana L.M. Barretto²*, Marleyne J.A.A.L. Amorim² ${ }^{2}$ e Marcus V.D. Falcão ${ }^{2}$
}

\begin{abstract}
Barretto M.L.M., Amorim M.J.A.A.L. \& Falcão M.V.D. 2013. [Morphological analysis of gonads of sloth (Bradypus variegatus Schinz, 1825).] Análise morfológica e morfométrica das gônadas de preguiça (Bradypus variegatus Schinz, 1825). Pesquisa Veterinária Brasileira 33(9):1130-1136. Área de Anatomia, Departamento de Morfologia e Fisiologia Animal, Universidade Federal Rural de Pernambuco, Rua Dom Manoel de Medeiros s/n, Dois Irmãos, Recife, PE 52171-900, Brazil. E-mail: mariana.lumack@gmail.com

The sloth can be zoologically designated as a mammal from class Eutheria, order Edentata, suborder Xenarthra and family Bradypodidae. The genus Bradypus is constituted by three different species: B. tridactylus, restricted to the Amazon region, B. variegatus, widely distributed through Central and South Americas, and B. torquatus, the only in serious danger of extinction. There's a need to investigate more deeply the B. variegatus, to effectivelly contribute to the literature of wild species' anatomy, besides search for more informations about the anatomy of the reproductive system of the sloth (Bradypus variegatus Schinz, 1825) and so, apply the new knowledge into the preservation of this species. We used four males and three females individuals, from the species' bank of the Anatomy Area, Department of Animal Morphology and Physiology, Federal Rural University of Pernambuco (DMFA/UFRPE) which were dissected and we evidenced the gonads' vascularization, as well as its localizations, morphological aspects and morphometric data of the analyzed testicles and ovaries. As results, it was seen that the male has internal testicles, connected to the adrenal glands by a ligament of peritoneum. The vascularization is not made by a pampiniform plexus, but by one testicular artery and vein. The testicles have, in average, volume equals to $1.42 \mathrm{~cm}^{3}$; thickness, width and length, respectively equals to $0.98,1.23$ and $1.45 \mathrm{~cm}$. The ovaries are also inside the intra-abdominal space, above the uterus, protected by an ovarian bursa, consistuted by mesovary and mesosalpinx. The vascularization is made by an arteriovenous plexus, which irrigates and drains the uterus, and its ramifications over the uterine wall reaches the ovaries. The ovaries have, in average, thickness, width and length, respectively equals to $0.37,0.73$ and $0.62 \mathrm{~cm}$.
\end{abstract}

INDEX TERMS: Morphology, morphometry, gonads, ovary, testicle, sloth, Bradypus variegatus.

RESUMO.- A preguiça pode ser designada, zoologicamente, como um mamífero da classe Eutheria, ordem Edentata, subordem Xenarthra e família Bradypodidae. 0 gênero Bradypus é constituído de três espécies distintas: a preguiça-de-bentinho (B. tridactylus), restrita à região amazônica; a preguiça-comum (B. variegatus), de ampla distribuição, ocorrendo nas Américas Central e do Sul e a preguiça-de-

\footnotetext{
${ }^{1}$ Recebido em 21 de fevereiro de 2013.

Aceito para publicação em 19 de julho de 2013.

2 Área de Anatomia, Departamento de Morfologia e Fisiologia Animal, Universidade Federal Rural de Pernambuco (UFRPE), Rua Dom Manoel de Medeiros s/n, Dois Irmãos, Recife, PE 52171-900, Brasil. *Autor para correspondência: mariana.lumack@gmail.com
}

-coleira (B. torquatus), única seriamente ameaçada de extinção. Percebe-se a necessidade de uma investigação mais aprofundada sobre a espécie $B$. variegatus, a fim de contribuir de forma efetiva com a elaboração de tratados de anatomia da fauna silvestre, além de buscar mais informações sobre a anatomia do sistema reprodutor do bicho preguiça (Bradypus variegatus Schinz, 1825) e, desta forma, aplicar os novos conhecimentos na sua preservação. Utilizamos quatro indivíduos machos e três fêmeas, pertencentes ao banco de espécies da Área de Anatomia do Departamento de Morfologia e Fisiologia Animal da Universidade Federal Rural de Pernambuco (DMFA/UFRPE), as quais foram dissecados e evidenciamos a vascularização das gônadas, bem 
como suas localizações e aspectos morfológicos e morfométricos dos testículos e ovários. Como resultados, observou-se que o macho possui testículos localizados no interior do espaço intraabdominal, ligados às glândulas adrenais por um ligamento de peritônio. A vascularização não é feita por um plexo pampiniforme, mas por uma artéria e uma veia testicular. Os testículos possuem, em média, volume igual a $1,42 \mathrm{~cm}^{3}$ e espessura, largura e comprimento, respectivamente iguais a $0,98,1,23$ e 1,45cm. Os ovários também estão no interior do espaço intra-abdominal, no fundo do útero, protegidos por uma bolsa ovariana, composta por mesovário e mesossalpinge. A vascularização é realizada por um plexo arteriovenoso que irriga e drena o útero, e suas ramificações na parede uterina atingem os ovários. Os ovários possuem, em média, espessura, largura e comprimento, respectivamente iguais a 0,37, 0,73 e 0,62 cm.

TERMOS DE INDEXAÇÂO: Morfologia, morfometria, gônadas, ovário, testículo, preguiça, Bradypus variegatus.

\section{INTRODUÇÃO}

O gênero Bradypus é constituído de três espécies distintas: preguiça-de-bentinho (Bradypus tridactylus), restrita à região amazônica; preguiça-comum (Bradypus variegatus), de mais ampla distribuição, ocorrendo nas Américas Central e do Sul, desde a Costa Rica, incluindo Equador, Colômbia, Venezuela, Peru, Bolívia, Argentina e praticamente todo o Brasil; preguiça-de-coleira (Bradypus torquatus), única seriamente ameaçada de extinção, está restrita às florestas remanescentes da Mata Atlântica nos estados da Bahia, Espírito Santo e do Rio de Janeiro (Wetzel \& Avila-Pires 1980, Eisenberg 1981). O bicho preguiça é encontrado nas regiões de floresta tropical da América, desde Honduras e Nicarágua, mais ao norte, pelo Panamá, e mais ao sul pelo Brasil e Bolívia. Ocorre em ambos os lados dos Andes, um fato que os primeiros observadores não reconheceram. Bradypus ocorre somente em baixas altitudes neotropicais, e prevalece em regiões onde a temperatura não varia muito, como florestas tropicais (Britton 1941).

As investigações relativas ao desenvolvimento pós-natal do testículo de mamíferos são importantes sobre o ponto de vista de vários aspectos ligados à reprodução, como por exemplo, estudos biométricos e histométricos podem auxiliar na caracterização da puberdade e maturidade sexual, além de dar suporte a estudos comparativos com animais de outras espécies (Assis Neto 2003). Conhecimentos sobre a anatomia e histologia do trato genital feminino é crucial para futuro sucesso reprodutivo de programas de conservação de espécies (Rossi 2011).

A biologia reprodutiva das xenarthras ainda apresenta muitas incógnitas, principalmente no que se refere ao comportamento reprodutivo e à fisiologia endócrina, do ciclo estral (Snoeck 2010) à gestação (Amorim 2003, Miranda \& Costa 2007). Preguiças machos e fêmeas são difíceis de serem distinguidos, exceto pela marca dorsal em Bradypus (Britton 1941).

Os machos de Bradypus possuem pênis rudimentar e testículos pequenos e arredondados, que se localizam perto um do outro dentro da cavidade abdominal, entre o reto e a vesícula urinária. Assim, a espermatogênese ocorre na mesma temperatura corporal, que é inferior em comparação à maioria dos mamíferos (Gilmore \& Peres-Costa 1995). Vesículas seminais foram observadas em Bradypus e Choloepus, grandes no primeiro e pequenas no último (Wislocki 1928). Os testículos intra-abdominais em todas as preguiças são muito pequenos - apenas $0,13 \%$ do peso corporal (Britton 1941).

O útero das preguiças possui uma única cavidade, trompas uterinas enroladas, ovários escondidos e bilobados, com uma fenda funda no hilo, e uma bolsa ovárica formada de uma dobra do mesossalpinge. Os ovários contêm folículos primários, folículos de Graaf e ocasionalmente um corpo lúteo (Weber 1894). 0 ovário é bilobado e é localizado em uma bolsa uterina. A vagina é dupla em seu terço caudal, e dessa maneira, possui duas pequenas saídas (Britton 1941). Apresentam o clitóris bem desenvolvido, sendo às vezes encurvado. A vagina é característica, pois em seu terço caudal é dobrada, constituída de duas saídas estreitas que, durante um certo período, são completamente obstruídas por uma membrana. 0 canal genital e o ânus abrem-se em uma pseudocloaca, com cerca de 8 a 12 glândulas de Bartholin nas paredes laterais do seio urogenital (Goffart 1971).

Sabe-se que, para salvar uma espécie da extinção, é necessário reduzir as ameaças, viabilizando as populações, além de dominar a reprodução do animal em cativeiro e a maneira de alimentá-lo (Soulé 1987, Martins 2007). Caracterizar o sistema reprodutor masculino e feminino da espécie em questão é o primeiro passo para o desenvolvimento e sucesso de programas de reprodução em cativeiro. Diante dos conhecimentos expostos, percebe-se a necessidade de uma investigação mais aprofundada, a fim de contribuir de forma efetiva com a elaboração de tratados de anatomia da fauna silvestre, além de buscar mais informações sobre a anatomia do sistema reprodutor do bicho preguiça (Bradypus variegatus Schinz, 1825) e, desta forma, aplicar os novos conhecimentos na sua preservação.

\section{MATERIAL E MÉTODOS}

O estudo foi realizado nas dependências da Área de Anatomia do Departamento de Morfologia e Fisiologia Animal da Universidade Federal Rural de Pernambuco. A pesquisa foi aprovada pela Comissão de Ética no Uso de Animais (CEUA), sob a licença no $16 / 2011$. Utilizaram-se sete animais pertencentes ao banco de espécies da Área de Anatomia do Departamento de Morfologia e Fisiologia Animal da Universidade Federal Rural de Pernambuco (DMFA/UFRPE), sendo duas fêmeas gravídicas, uma fêmea adulta não gravídica, três machos adultos e um macho jovem.

Os sete animais utilizados na pesquisa foram injetados com solução aquosa de formaldeído à 10\%, e conservados em tanques com solução de mesma concentração. Seguidamente, três machos e uma fêmea gravídica foram injetados com látex Neoprene 650 (DuPont ${ }^{\circledR}$ ), com pigmentos específicos vermelho e azul.

Os animais utilizados foram dissecados iniciando-se por uma laparotomia na região retro-umbilical para a observação in situ dos órgãos internos, da sintopia e esqueletopia das gônadas e visualização das estruturas de sustentação dos testículos e dos ovários. Dissecou-se a vascularização das gônadas e rins, desde vasos magnos como a aorta e a veia cava caudal, até os vasos de menor 
calibre, como as veias e artérias testiculares e os plexos arteriovenosos ovarianos detectados nesta espécie.

Ao final da dissecação, utilizou-se paquímetro manual para obtenção dos dados morfométricos, como comprimento, largura e espessura dos testículos e ovários. Para os parâmetros biométricos testiculares e ovarianos, foram realizadas análises descritivas de média e desvio padrão através do programa Microsoft Excel® 2007. Para os animais machos, aplicou-se a fórmula de volume testicular, $V=4 / 3 \pi \cdot a \cdot b^{2}$, onde $a$ é igual à metade do comprimento do testículo e $b$ é igual à metade da largura do testículo (Woodal \& Johnstone 1988). As etapas de dissecação foram fotodocumentadas com câmera digital Nikon Coolpix P100 10.3 mp.

\section{RESULTADOS}

Os testículos do bicho preguiça (Bradypus variegatus) localizam-se no interior do espaço intraabdominal, envolvidos por túnica vaginal, composta por peritônio visceral. Apresenta formato ovalado, com duas superfícies, duas bordas e duas extremidades. A superfície dorsal é achatada, devido à sintopia com o reto, e a superfície ventral é levemente abaulada. A borda livre é medial e a borda epididimária é lateral. As extremidades cranial e caudal são convexas. Os testículos fazem sintopia com o estômago, o reto, a vesícula urinária, os rins, o intestino delgado e os ureteres. Existe esqueletopia com o osso coxal (Fig.1A).
Dos quatro machos analisados, os três animais adultos possuem os testículos localizados caudomediais aos rins, enquanto que o exemplar jovem apresentou testículos laterais aos rins e inclinados diagonalmente, e não verticais como nos adultos. Em todos os espécimes, existe um ligamento formado por peritônio entre o testículos e as glândulas adrenais dos respectivos antímeros (Fig.1B).

Em cada rim, existe um ramo venoso cranial e um caudal, que se configuram como ramos da veia renal. Em ambos os antímeros, a veia testicular emerge do testículo, junto à artéria testicular e ao ligamento de peritônio gônada-adrenal, e desemboca no ramo cranial da veia renal. Um pequeno ramo venoso vindo de cada glândula adrenal também desemboca na respectiva veia testicular. Em seguida, os ramos cranial e caudal das veias renais desembocam no respectivo ramo da veia cava caudal. Estes ramos se unem cranialmente aos rins,tornando-se apenas uma única veia cava caudal, a qual segue em direção ao átrio direito do coração. A aorta abdominal envia uma artéria renal para cada rim, e desta parte uma artéria testicular em direção aos testículos, juntamente à veia testicular e ao ligamento gônada-adrenal. Não foi observada a presença de plexo pampiniforme (Fig.1C,D).

Em relação à morfometria testicular, os parâmetros

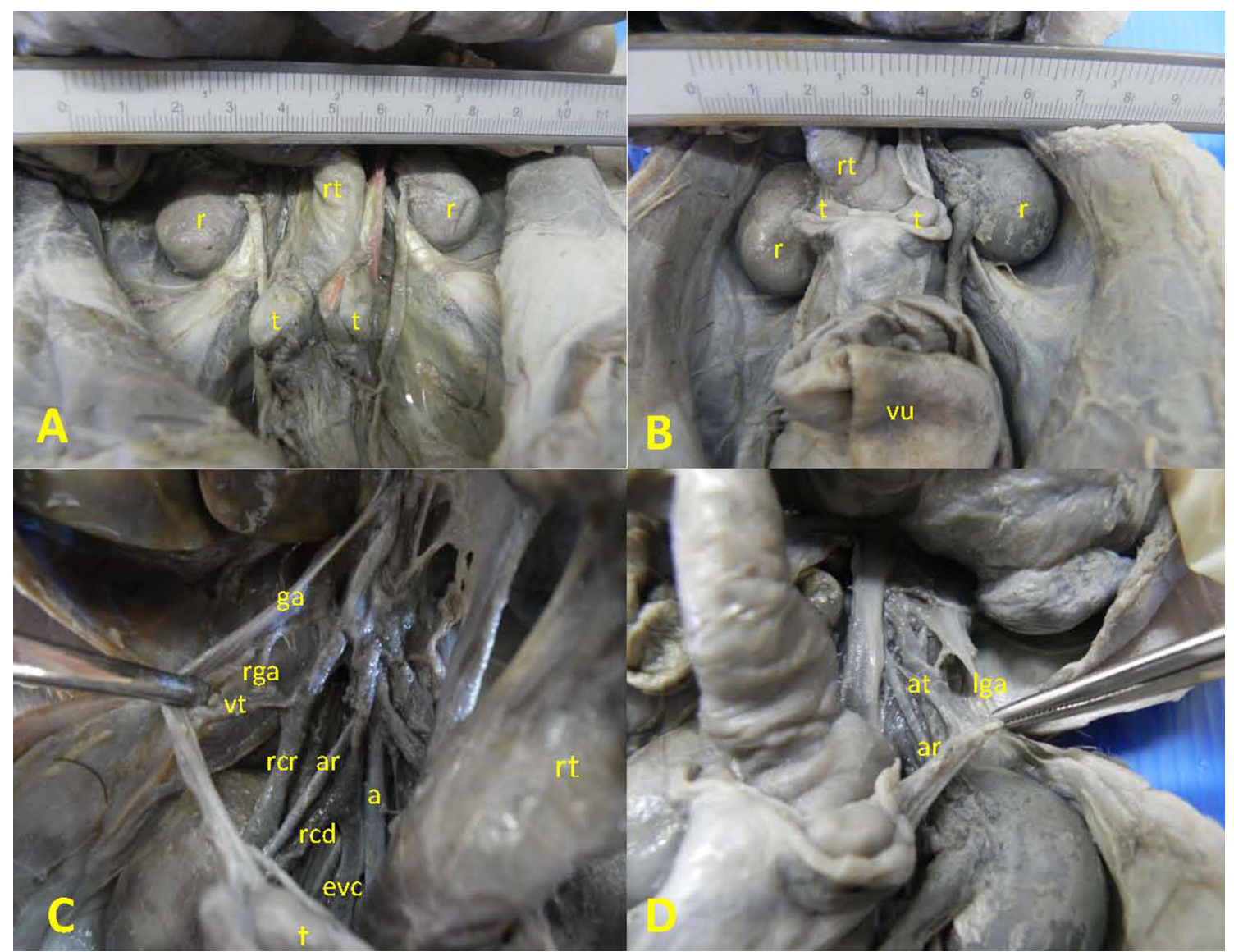

Fig.1. Vista ventral do espaço intraabdominal de Bradypus varigatus macho. (A) Adulto. Rim (r), testículo (t), reto (rt). (B) Jovem. Rim (r), testículo (t), reto (rt), vesícula urinária (vu). (C) Reto (rt), testículo (t), glândula adrenal (ga), veia testicular (vt), ramo venoso da glândula adrenal (rga), ramo cranial da veia renal (rcr), ramo caudal da veia renal (rcd), artéria renal (ar), aorta (a), ramo esquerdo da veia cava caudal (evc). (D) Artéria renal (ar), artéria testicular (at), ligamento gônada-adrenal (lga). 
$\square$ Volumetesticular $\left(\mathrm{cm}^{3}\right) \quad$ Espessura $(\mathrm{cm}) \quad$ Largura $(\mathrm{cm}) \quad \square$ Comprimento $(\mathrm{cm})$

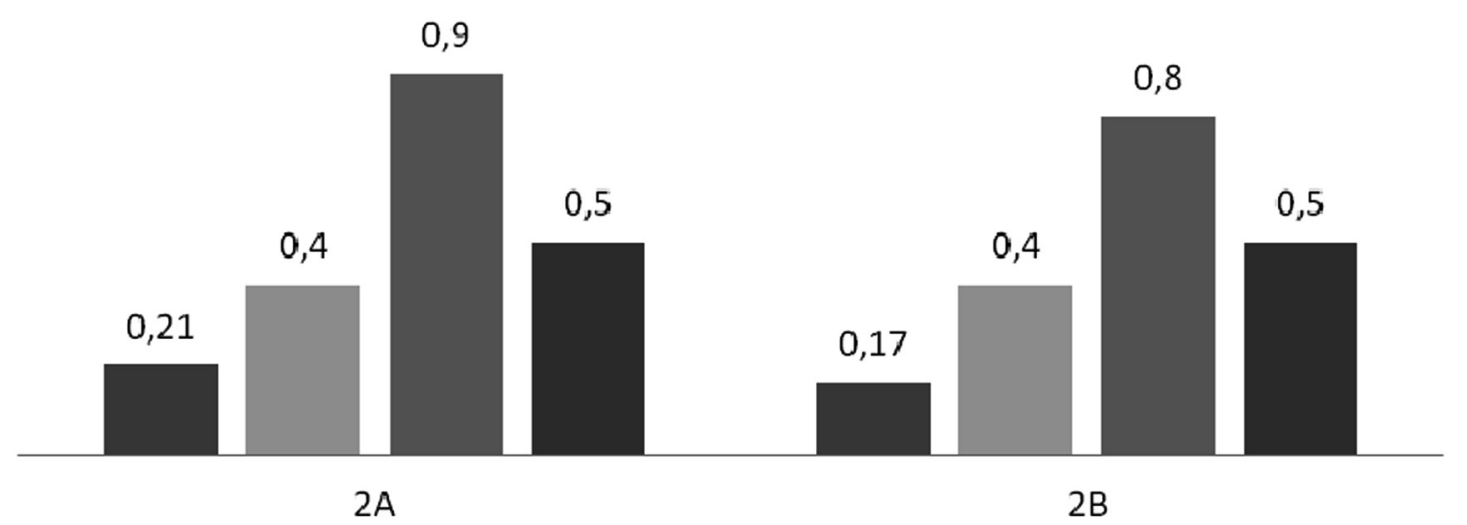

Fig.2. Morfometria testicular de Bradypus variegatus jovem.

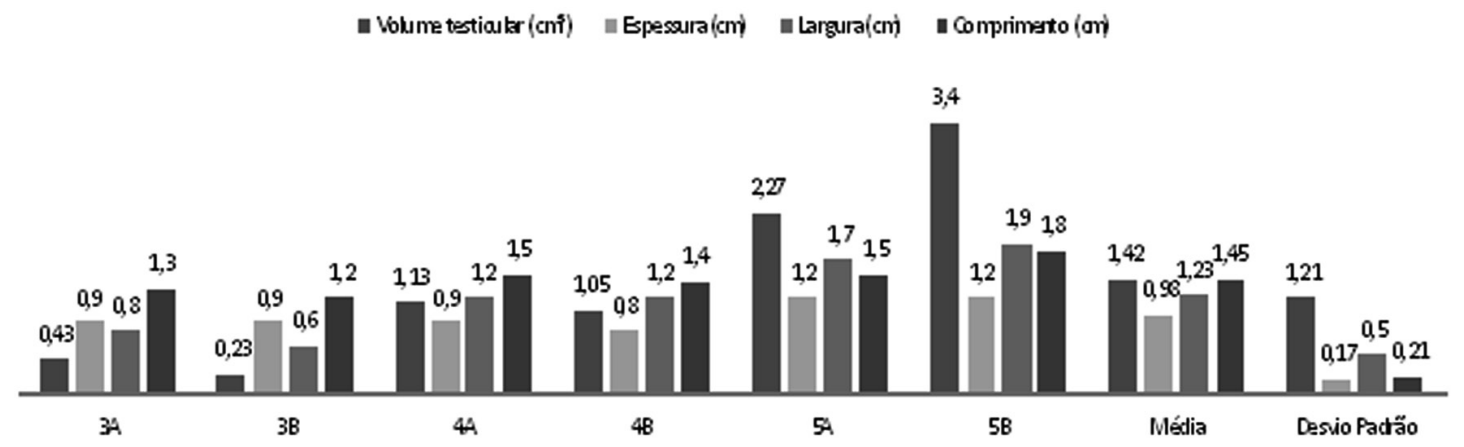

Fig.3. Morfometria testicular de Bradypus variegatus adulto.

biométricos, assim como as médias e desvios padrão estão representados em gráficos (Fig.2 e 3). Para o macho jovem (Fig.2), o volume testicular, a espessura, a largura e o comprimento dos testículos mediram, respectivamente, $0.21 \mathrm{~cm}^{3}, 0.4,0,9$ e 0.5 para o testículo esquerdo e $0.17 \mathrm{~cm}^{3}$, $0.4,0.8$ e $0.5 \mathrm{~cm}$ para o testículo direito. Entre os machos adultos (Fig.3), o volume testicular, a espessura, a largura e o comprimento dos testículos variaram, respectivamente, de 0.23 a $3.4 \mathrm{~cm}^{3}(1.42 \pm 1.21), 0.8$ a $1.2 \mathrm{~cm}(0.98 \pm 0.17), 0.6$ a $1.9 \mathrm{~cm}(1.23 \pm 0.5)$ e 1.2 a $1.8 \mathrm{~cm}(1.45 \pm 0.21)$.

Os ovários do bicho preguiça localizam-se no interior do espaço intraabdominal, posicionados sobre a parede uterina externa, um em cada lado do fundo do útero, o qual tem formato periforme (Fig.4A). Estão protegidos por uma bolsa ovariana, que possui uma estreita abertura dorsal, e é formada por uma extensão do mesossalpinge e por mesovário. Inserida na porção do mesossalpinge que compõe a bolsa ovariana, encontra-se a tuba uterina, que atinge o ovário na extremidade cranial (Fig.4B). Os ovários fazem sintopia com o mesossalpinge, o mesovário, as tubas uterinas, o útero, o estômago, o intestino delgado e o reto, e existe esqueletopia com o osso coxal. São ovalados, achatados craniocaudalmente e possuem duas extremidades, duas superfícies e duas bordas. A extremidade cranial ou tubária está em contato com a bolsa ovariana, e a extremidade caudal ou uterina está em contato com a parede uterina, sendo conectado ao útero pelo pequeno ligamento ovariano. As superfícies lateral e medial encontram-se em contato com a bolsa ovariana. A borda mesovárica é dorsal, e a borda livre é ventral. Não foi observada a presença do ligamento suspensório do ovário (Fig.4C).

Não foi observada vascularização direta dos ovários como foi observada nos testículos. Existe um plexo arteriovenoso que irriga e drena o útero, e as ramificações destes vasos sobre a parede uterina atingem os ovários através da extremidade caudal, irrigando e drenando os mesmos. Em ambos os rins, existe um ramo cranial e um ramo caudal da veia renal. No antímero direito, um plexo venoso vindo do lado direito do útero (e do ovário direito) envia ramificações para o ramo direito da veia cava caudal e para a veia cava caudal acima da união de seus ramos direito e esquerdo. Este ramo venoso recebe uma veia da glândula adrenal. A aorta, por sua vez, envia uma artéria renal, e desta partem ramificações arteriais para o plexo, de onde a glândula adrenal recebe suas artérias. No antímero esquerdo, o plexo venoso oriundo do lado esquerdo do útero (e do ovário esquerdo) se une aos ramos cranial e caudal da veia renal e ao ramo esquerdo da veia cava caudal, unificando-se. Em seguida, o plexo recebe uma veia oriunda da glândula adrenal, formando o ramo esquerdo da veia cava caudal, o qual se une ao ramo direito, originando a veia cava caudal única. A aorta emite a artéria renal, e desta parte um ramo, que se divide e se enovela no plexo, até atingir a parede uterina. A glândula adrenal recebe uma artéria vinda do plexo arteriovenoso. Não existe ligamento de peritônio entre os ovários e as glândulas adrenais (Fig.4D).

Sobre a morfometria ovariana, os parâmetros biométricos, as médias e desvios padrão estão representados em 


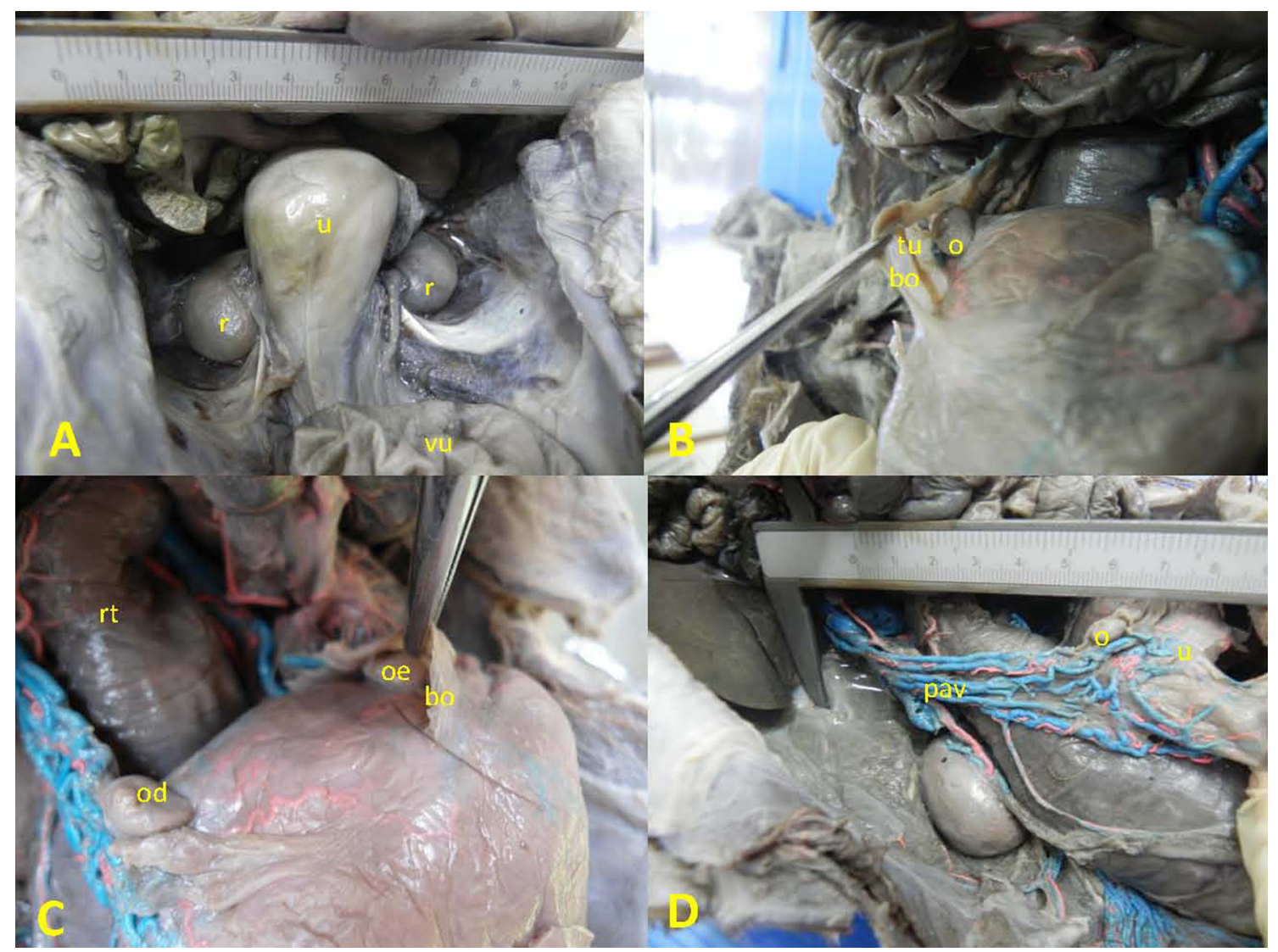

Fig.4. Vista ventral do espaço intraabdominal de Bradypus variegatus fêmea. (A) Útero (u), rim (r), vesícula urinária (vu). (B) Ovário (o), bolsa ovariana (bo), tuba uterina (tu). (C) Ovário direito (od), ovário esquerdo (oe), bolsa ovariana (bo), reto (rt). (D) Ovário (o), útero (u), plexo arteriovenoso (pav).

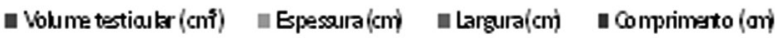

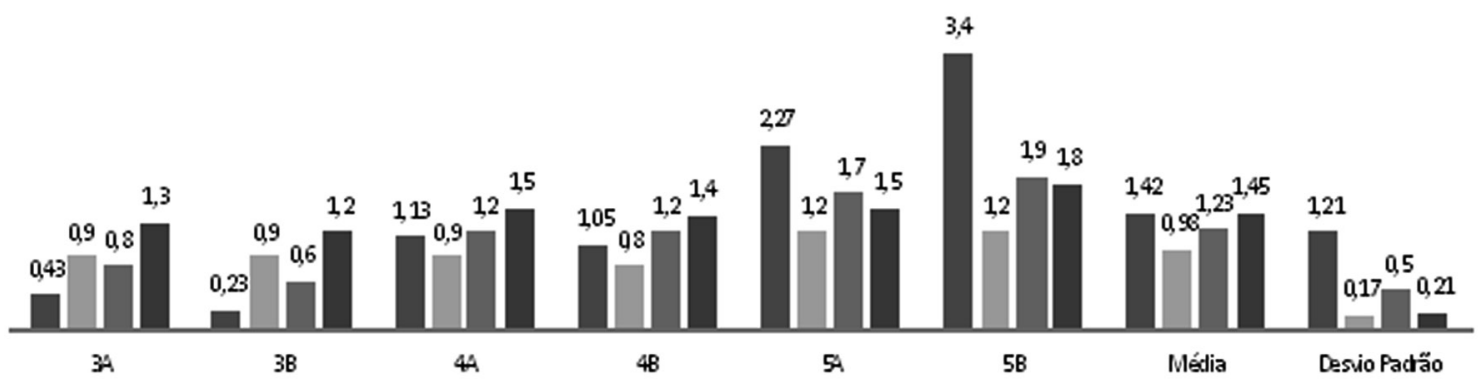

Fig.5. Morfometria ovariana de Bradypus variegatus adulta gravídica e não-gravídica.

gráfico (Fig.5). A espessura, a largura e o comprimento dos ovários mediram, respectivamente, 0.3 a $0.4 \mathrm{~cm}(0.37 \pm 0.05)$, 0.6 a $0.8 \mathrm{~cm}(0.73 \pm 0.08)$ e 0.5 a $0.8 \mathrm{~cm}(0.62 \pm 0.15)$.

\section{DISCUSSÃO}

Os resultados mostram que os testículos dos Bradypus variegatus possuem a superfície dorsal achatada e a superfície ventral abaulada, contrastando com os resultados obtidos por Martins (2003), que descreve que em preguiças-de-coleira os testículos possuem as superfícies dorsal abaulada e ventral achatada.

Observou-se que os testículos do indivíduo jovem localizam-se lateralmente aos rins e os testículos dos adultos estão caudomediais aos rins. Pela presença do ligamento gônada-adrenal, é possível inferir que existe uma descida testicular parcial, dentro do próprio espaço intraabdominal, proporcionada pela flexibilidade do ligamento, fato também constatado por Martins (2003), em Bradypus torquatus. Desta forma, a localização testicular em relação aos rins vem a ser um critério de identificação da faixa etária à qual o animal pertence. Nota-se que tal ligamento possui função semelhante ao gubernáculo, estrutura que orienta a descida testicular. Quanto à morfometria, observou-se em Bradypus variegatus que o comprimento é o fator de maior variação entre o macho jovem e o macho adulto, sendo possível existir uma verticalização testicular à medida que o animal se desenvolve. Em Tamandua tetradactyla, o comprimento, largura, espessura e volume testicular variaram, 
respectivamente, entre 2.0 e $3.6 \mathrm{~cm}, 1.0$ a $2.4 \mathrm{~cm}, 0.8$ a $1.5 \mathrm{~cm}$ e 1.0 a $10.8 \mathrm{~cm}^{3}$ (Rossi 2013).

A ausência de plexo pampiniforme poderia ser explicada pelo baixo metabolismo e consequente baixa temperatura corporal da espécie, pois não seria uma estrutura de grande necessidade para a manutenção da temperatura sanguínea, se esta já é mais baixa. Ainda que não exista tal estrutura, a veia e a artéria testicular correm paralelamente, junto ao ligamento gônada-adrenal, então é possível que exista uma troca de calor entre estes vasos, simulando a função do plexo pampiniforme.

Os ovários do bicho preguiça localizam-se aderidos à parede externa do fundo do útero, algo não observado dentre as espécies domésticas. Além disso, estão contidos dentro de uma bolsa ovariana, composta por mesovário e também por mesossalpinge, já que nela também encontram-se as tubas uterinas. Na espécies Chaetophractus vellerosus, Zaedyus pichiy e Dasypus hybridus, existe um par de ovários fixados na região sublombar pela porção anterior do ligamento largo do útero, o mesovário. Estão em ambos os lados da região cranial do útero e são localizados caudalmente e lateralmente aos rins. 0 ligamento ovariano se estende desde a extremidade uterina até o fundo do útero (Códon \& Casanave 2000). Em Tamandua tetradactyla, os ovários foram observados como estruturas ovóides. 0 comprimento, largura e espessura ovarianos variaram entre 5.0 e $23.0 \mathrm{~cm}, 4.0$ e $10.0 \mathrm{~cm}$ e 4.0 a $10.0 \mathrm{~cm}$ (Rossi 2011).

As fêmeas possuem uma característica peculiar no que se refere à vascularização dos ovários. Existe um plexo arteriovenoso que irriga e drena o útero, e ramificações deste plexo atingem os ovários, irrigando-os e drenando-os. A fêmea, assim como o macho, possui a veia renal dupla, sendo um ramo cranial e um ramo caudal, mas apenas no antímero esquerdo existe interação direta entre a parte venosa do plexo e os ramos venosos renais, além da continuação do ramo esquerdo da veia cava caudal. Já no antímero direito, o plexo comunica-se diretamente com o ramo direito da veia cava caudal e envia um ramo para a veia cava caudal única. Em Bradypus torquatus, a artéria uterina enovela-se bastante na face lateral, entremeando a musculatura uterina,provavelmente pela necessidade de estiramento do vaso para acompanhar a distensão da musculatura, por exemplo, nas gestações, evitando a ruptura dos vasos (Pompeu \& Silva 2010).

Com a morfometria ovariana, demonstrou-se que os ovários de ambos os antímeros da fêmea não-gravídica apresentam as mesmas medidas, algo não constatado nos ovários das fêmeas gravídicas. Assim, pode-se supor que exista um intumescimento ovariano durante a gestação, que poderia ser causado pela presença de um corpo lúteo, caso Bradypus variegatus seja uma espécie corpo lúteo-dependente, ou apenas pelo crescimento do folículo ovariano que liberou o ovócito.

\section{CONCLUSÕES}

Com os resultados anatômicos encontrados, afirma-se que existe, no macho, descida testicular parcial dentro do espaço intraabdominal, sendo esta uma forma de identifi- cação da faixa etária do animal. Existe um sistema de contracorrente entre a veia e a artéria testicular, já que estes vasos correm paralelamente, juntamente a um ligamento de peritônio, o qual liga as glândulas adrenais aos testículos dos respectivos antímeros. Este sistema é semelhante ao mecanismo observado nos mamíferos domésticos.

Na fêmea, a presença do plexo arteriovenoso é um fato peculiar. Além disso, é possível que o bicho preguiça seja uma espécie corpo lúteo-dependente, pela variação do tamanho entre os ovários esquerdo e direito das fêmeas gravídicas.

Para a elucidação das questões levantadas neste trabalho, são necessárias pesquisas histofisiológicas reprodutivas da espécie.

Agradecimentos.- À professora Marleyne Amorim pela orientação; ao Conselho Nacional de Desenvolvimento Científico e Tecnológico (CNPq), pelo financiamento da pesquisa.

\section{REFERÊNCIAS}

Amorim M.J.A.A.L., Miglino M.A., Amorim Júnior A.A. \& Santos T.C. 2003. Aspectos morfológicos da placenta da preguiça (Bradypus variegatus Shinz, 1825). Braz. J. Vet. Res. Anim. Sci. 40:217-226.

Assis-Neto A.C., Carvalho M.A.M., Melo M.I.V., Miglino M.A., Oliveira M.F., Almeida M.M., Papa P.C. \& Kfoury Junior J.R. 2003. Aspectos biométricos do desenvolvimento testicular e corporal em cutias (Dasyprocta aguti) criadas em cativeiros. Braz. J. Vet. Res. Anim. Sci. 40(2):154-160.

Britton S.W. 1941. Form and function in the sloth. Quart. Rev. Biol. 16:190207.

Códon S.M. \& Casanave E.B. 2000. Morfología comparada del ovario de tres especies de dasipódidos (Mammalia, Xenarthra). Rev. Chil. Anat. 18 2:251-257.

Eisenberg J.F. 1981. The Mammalian Radiations: an analysis of trends in evolution, adaptations, and behavior. University of Chicago Press, Chicago. 610p.

Gilmore D.P. \& Peres-Costa C. 1995. The three-toed sloth in biomedical research: an update on the reproductive and endocrine systems. Med. Sci. Res. 23:579-581.

Goffart M. 1971. Function and Form in the Sloth. Pergamon Press, Oxford. 225p.

Martins D.S. 2003. Morfologia do sistema reprodutor masculino da preguiça-de-coleira (Bradypus torquatus Illiger, 1811). Dissertação de Mestrado em Anatomia dos Animais Domésticos e Silvestres, Faculdade de Medicina Veterinária e Zootecnia, Universidade de São Paulo, SP. $116 \mathrm{p}$.

Martins D.S., Ferreira J.R., Ambrósio C.E., Azarias R.E., Oliveira V.L., Machado M.R.F. \& Miglino M.A. 2007. Análise estrutural das glândulas genitais acessórias da preguiça de coleira (Bradypus torquatus Illiger, 1811). Biotemas 20(2):89-97.

Miranda F. \& Costa A.M. 2007. Xenarthra (tamanduá, tatu e preguiça), p.402-414. In: Cubas Z.S., Silva J.C.R. \& Catão-Dias J.L. (Eds), Tratado de Animais Selvagens: medicina veterinária. Roca, São Paulo.

Pompeu e Silva M., Rezende L.C., Alcântara D. \& Miglino M.A. 2010. Análise comparativa da morfologia uterina do bicho preguiça, tamanduá e tatu (Xenarthras). Enciclop. Biosfera 6(10):1-7.

Rossi L.F., Luaces J.P., Aldana Marcos H.J., Cetica P.D., Gachen G., Pérez Jimeno G. \& Merani M.S. 2011. Female reproductive tract of the lesser anteater (Tamandua tetradactyla, Myrmecophagidae, Xenarthra): anatomy and histology. J. Morphol. 272:1307-1313.

Rossi L.F., Luaces J.P., Aldana Marcos H.J., Cetica P.D., Pérez Jimeno G. \& Merani M.S. 2013. Anatomy and histology of the male reproductive tract and spermatogenesis fine structure in the lesser anteater (Tamandua tetradactyla, Myrmecophagidae, Xenarthra): morphological evidences of reproductive functions. Anat. Histol. Embryol. 42(4):247-56. 
Snoeck P.P.N., Cruz A.C.B., Catenacci L.S. \& Cassano C.R. 2011. Citologia vaginal de preguiça-de-coleira (Bradypus torquatus). Pesq. Vet. Bras. 31(3):271-275.

Soulé M.E. 1987. Viable Populations for Conservation. Cambridge University Press, Cambridge. 189p.

Weber M. 1894. Beiträge zur Entwicklung und Anatomie des Genus Manis. Zool. Ergebn. einer Reise nach Niederl. Ostindien 2:57. (Apud Goffart M. 1971, p.144)
Wetzel R.M. \& Avila-Pires F.D. 1980. Identification and distribution os the recent sloths of Brazil (Edentata). Revta Bras. Biol. 40:831-836.

Wislocki G.B. 1928. Observations on the gross and microscopic anatomy os the sloths (Bradypus griseus griseus Gray and Choloepus hoffmanni Peters). J. Morphol. Physiol. 46:317-397.

Woodal P.F. \& Johnstone I.P. 1988. Scrotal width as an index of testicular size in dogs and its relationship to body size. J. Small Anim. Pract. 29:543-547. 